Int. J. Dev. Biol. 61: 383-387 (2017)

doi: $10.1387 / \mathrm{ijdb} .170021 \mathrm{LS}$

\title{
Interactions among gibberellins, brassinosteroids and genes regulate stomatal development in the Arabidopsis hypocotyl
}

\author{
DIEGO GONZÁLEZ, SONIA FUENTES and LAURA SERNA* \\ Facultad de Ciencias Ambientales y Bioquímica, Universidad de Castilla-La Mancha, Toledo, Spain
}

\begin{abstract}
Stomata are pores on the plant surface that enable gas exchange with the atmosphere. In Arabidopsis thaliana, brassinosteroids, which function upstream of the TTG/bHLHs/MYBs/GL2 transcriptional network, positively regulate stomatal formation in the hypocotyl. Gibberellins also promote stomatal development in the embryonic stem. Here, we investigated the hypothetical interactions between the gibberellin and brassinosteroid signaling pathways during stomatal formation. By combining genetics and gene expression studies, we found that gibberellins promote stomatal development, functioning upstream of both brassinosteroids and the TTG/bHLHs/MYBs/ GL2network. Gibberellins also regulate an earlier step in stomatal development than that regulated by the receptor-like membrane protein TOO MANY MOUTHS.
\end{abstract}

KEY WORDS: Arabidopsis thaliana, brassinosteroid, gibberellin, stomata

The simplicity of the hypocotyl epidermis of Arabidopsis Thaliana makes it an excellent model system for studying cell fate specification and patterning formation. This embryonic organ consists of only two types of epidermal cell files: non-stomata-forming cells and stomata-forming cells. Files devoid of stomata overlie a single cortical cell file, while their neighboring stomatal-forming files are located outside of two cortical cell files (Berger et al., 1998; Hung et al., 1998). In stomatal-forming files, stomatal development starts with an asymmetric division, which is parallel to the longitudinal axis of the cell (Berger et al., 1998). The smaller cell produced by this cell division, the meristemoid, is a self-renewing cell that undergoes a probabilistic sequence of cell divisions before producing the stoma (Berger et al., 1998). Beyond providing a framework for the study of a fundamental developmental mechanism, stomata are major components of the terrestrial water and carbon cycles.

Many of the genes controlling stomatal formation in the Arabidopsis hypocotyl encode transcription factors that are assembled into a multimeric complex. This complex, which consists of a protein with WD40 repeats named TRANSPARENT TESTA GLABRA (TTG), the R2R3MYB protein WEREWOLF, and two basic helix-loop-helix (bHLH) proteins known as GLABRA3 and ENHANCER OF GLABRA3, represses the formation of stomata in files overlying a single cortical cell file (Larkin et al., 2003; Schiefelbein, 2003; Serna, 2004 a; Serna, 2004 b). The function of this complex depends on its ability to induce the transcription of GLABRA2 (GL2), which encodes a homeodomain-leucine zipper protein (Rerie et al., 1994; Di Cristina et al., 1996), in epidermal cell files overlying a single cortical cell file (Larkin et al., 2003; Schiefelbein, 2003; Serna, 2004 a; Serna, 2004 b). Both stomatal development and the repression of $G L 2$ expression depend on the sequestration of GLABRA3 and ENHANCER OF GLABRA3 by the R3MYB proteins CAPRICE (CPC) and/or TRIPTYCHON (TRY) (Serna, 2008). This event promotes the formation of a complex consisting of CPC (and/or TRY), TTG, GLABRA3, and ENHANCER OF GLABRA3 (Serna, 2008). To form this complex, $C P C$ (and probably TRY), which is expressed in files characterized by the absence of stomata (Kirik et al., 2004; Serna, 2008), moves to the stomatal-forming cell files (Serna, 2008). In addition to this network, TOO MANY MOUTHS (TMM), which encodes a leucine-rich repeat receptor-like protein without a cytoplasmic domain (Nadeau and Sack, 2002), also controls stomatal formation (Geisler et al., 1998). This gene regulates later stages than that regulated by the TTG/bHLHs/MYBs/GL2 network, promoting stomatal formation from the meristemoids (Bhave et al., 2009).

Phytohormones also regulate this process. Both brassinosteroids (Fuentes et al., 2012; Gudesblat et al., 2012) and gibberellins (Saibo et al., 2003) positively regulate stomatal formation, with ethylene and auxin modulating the action of gibberellins (Saibo et

Abbreviations used in this paper: CPC, CAPRICE; GFP, GREEN FLUORESCENT PROTEIN; GL2, GLABRA2; TMM, TOO MANY MOUTHS.

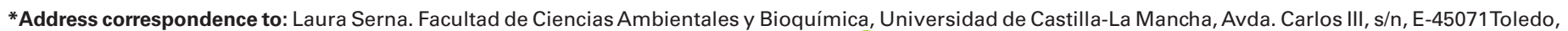
Spain. Tel: 34-925-268800 Ext.: 5467. Fax: 34-925-268840. E-mail: laura.serna@uclm.es - (iD) http://orcid.org/0000-0002-4705-3519
}

Submitted: 1 February, 2017; Accepted: 7 April, 2017; Edited by: Mieke van Lijsebettens.

ISSN: Online 1696-3547, Print 0214-6282 
al., 2003). In addition, brassinosteroids act upstream of the TTG/ MYBs/bHLHs/GL2 network to promote stomatal production in the Arabidopsis hypocotyl (Fuentes et al., 2012).

Many biological processes result from crosstalk among different hormonal signaling pathways. They include, for example, the integration of the primary signaling pathways of auxin and brassinosteroids by auxin response factor 2 (Vert et al., 2008), or the crosstalk between auxin and cytokinins and their antagonistic effects on plant immunity (Naseem et al., 2015). Brassinosteroidactivated BRASSINAZOLE RESISTANT1 (BZR1) and gibberellic acid-inactivated DELLA transcriptional regulators mediate also crosstalk between brassinosteroid and gibberellin pathways to regulate plant growth (Bai et al., 2012; Gallego-Bartolomé al., 2012; Li et al., 2012). Here, we investigate whether brassinosteroids and gibberellins act also in the same signaling pathway during stomatal development in the hypocotyl. We also delve into the interaction between the gibberellin signaling pathway and both the TTG/bHLHs/MYBs/GL2 transcriptional network and TMM.

\section{Results}

\section{Brassinosteroids act downstream of gibberellins}

Brassinosteroids and gibberellins promote stomatal formation in the hypocotyl (Saibo et al., 2003; Fuentes et al., 2012; Gudesblat et al., 2012; Table 1). In the current study, both epibrassinolide (0.5 $\mu \mathrm{M})$ and gibberellic acid $(10 \mu \mathrm{M})$ treatment increased the number of stomata per hypocotyl and the stomatal index in wild-type seedlings. In addition, the reduction in the endogenous production of these regulators in wild-type seedlings through treatment with $0.5 \mu \mathrm{M}$ paclobutrazol, which inhibits gibberellin biosynthesis (Rademacher, 2000), or $1 \mu \mathrm{M}$ triadimefon, which induces brassinosteroid deficiency-like phenotypes by binding to DWF4 (which is involved in brassinosteroid biosynthesis) (Asami et al., 2003), reduced stomatal production. These results indicate that the endogenous levels of these regulators are physiologically active.

As expected, mutants affected in gibberellin (gid1a-2 gid1b-3 gid1c-1) or brassinosteroid perception (bri1-1) did not develop stomata. Treatment of the gid1a-2 gid1b-3 gid1c-1 triple mutant
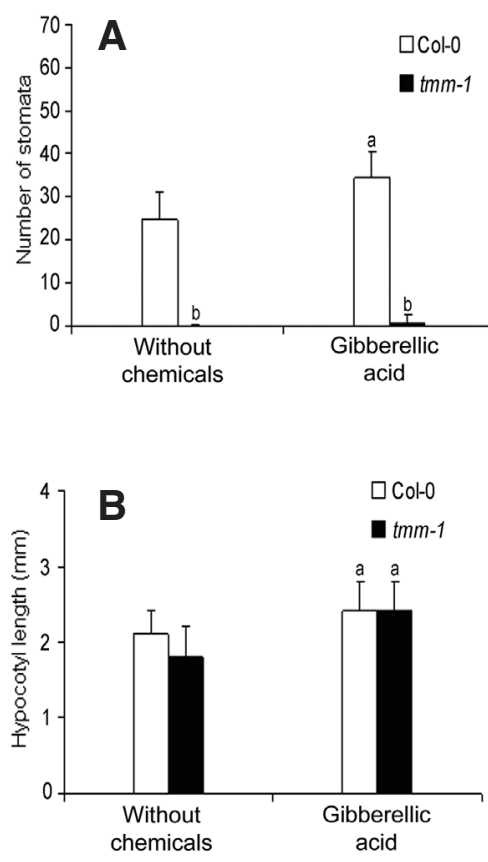

Fig. 1. Effect of gibberellic acid on the hypocotyls of wild-type and tmm-1 seedlings. (A) Number of stomata and (B) hypocotyl length of two-week-old wild-type plants and tmm-1 grown on media supplemented with $10 \mu \mathrm{M}$ gibberellic acid. Without chemicals denotes growth medium without added gibberellic acid. Values are mean e $S D(n \geq 15)$. ${ }^{a} \mathrm{Me}-$ ans are significantly different from those of plants grown without added gibberellic acid $(p<0.05)$. ${ }^{b}$ The difference between wild-type and tmm-1 seedlings is significant $(p<$ 0.05). The Student t-test was used to generate $p$ values.

with epibrassinolide $(0.5 \mu \mathrm{M})$ partially rescued both the number of stomata per hypocotyl and the stomatal index of this mutant (Table 1). This result suggests that brassinosteroids act downstream of gibberellins. In agreement with this interpretation, application of $10 \mu \mathrm{M}$ gibberellic acid to bri1-1 failed to rescue its stomatal phenotype (Table 1). Also as expected, stomatal production in wild-type seedlings grown on medium supplemented with $0.5 \mu \mathrm{M}$ epibrassinolide and $0.5 \mu \mathrm{M}$ paclobutrazol was higher than that in plants grown on medium supplemented only with paclobutrazol $(0.5 \mu \mathrm{M})($ Table 1$)$. The stomatal production of wild-type seedlings on medium supplemented with $10 \mu \mathrm{M}$ gibberellic acid and $1 \mu \mathrm{M}$ triadimefon was also higher than that of plants grown on medium supplemented only with triadimefon $(1 \mu \mathrm{M})$ (Table 1$)$. Under all growth conditions, stomata were located mainly in epidermal

TABLE 1

NUMBER OF STOMATA IN THE HYPOCOTYLS OF WILD-TYPE AND MUTANT SEEDLINGS GROWN WITH OR WITHOUT CHEMICAL TREATMENTS

\begin{tabular}{|c|c|c|c|c|c|c|}
\hline & \multicolumn{2}{|c|}{ Col-0 } & \multicolumn{2}{|c|}{ gid1a-2 gid1b-3 gid1c-1 (in Col-0) } & \multicolumn{2}{|c|}{ bri1-1 (in Col-0) } \\
\hline & $\begin{array}{c}\text { Number of } \\
\text { stomata per hypocotyl }\end{array}$ & $\begin{array}{c}\text { Stomatal } \\
\text { index }\end{array}$ & $\begin{array}{c}\text { Number of } \\
\text { stomata per hypocotyl }\end{array}$ & $\begin{array}{c}\text { Stomatal } \\
\text { index }\end{array}$ & $\begin{array}{c}\text { Number of stomata per } \\
\text { hypocotyl }\end{array}$ & Stomatal index \\
\hline Without chemical treatment & $\begin{array}{c}20.8 \pm 4.9 \\
(93.3)\end{array}$ & $8.6 \pm 2.7$ & $0.0 \pm 0.0^{\mathrm{a}}$ & $0.0 \pm 0.0^{\mathrm{a}}$ & $\begin{array}{c}0.3 \pm 0.5^{a} \\
(100)\end{array}$ & $0.6 \pm 1.8^{a}$ \\
\hline Epibrassinolide $(0.5 \mu \mathrm{M})$ & $\begin{array}{l}39 \pm 6.6^{\mathrm{D}} \\
(100.0)\end{array}$ & $12.2 \pm 1.7^{\mathrm{D}}$ & $\begin{array}{l}6.7 \pm 3.1^{\mathrm{a}, \mathrm{b}} \\
(100)\end{array}$ & $6.3 \pm 0.4^{\mathrm{a}, \mathrm{b}}$ & ND & ND \\
\hline Gibberellic acid $(10 \mu \mathrm{M})$ & $\begin{array}{c}38.3 \pm 6.6^{\mathrm{D}} \\
(100)\end{array}$ & $12.8 \pm 2.8^{\mathrm{D}}$ & ND & ND & $\begin{array}{c}0.3 \pm 0.5^{a} \\
(100)\end{array}$ & $1.7 \pm 2.6^{\mathrm{a}}$ \\
\hline Paclobutrazol $(0.5 \mu \mathrm{M})$ & $\begin{array}{c}7.7 \pm 3.7^{b} \\
(86.7)\end{array}$ & $6.5 \pm 1.2^{\mathrm{b}}$ & ND & ND & ND & ND \\
\hline Triadimefon $(1 \mu \mathrm{M})$ & $\begin{array}{l}15.2 \pm 4.3^{b} \\
(93.3)\end{array}$ & $6.5 \pm 2.5^{\mathrm{b}}$ & ND & ND & ND & ND \\
\hline $\begin{array}{l}\text { Epibrassinolide }(0.5 \mu \mathrm{M})+ \\
\text { Paclobutrazol }(0.5 \mu \mathrm{M})\end{array}$ & $12.7 \pm 3.8^{\mathrm{b}, \mathrm{c}}(90.7)$ & $9.9 \pm 1.6^{c}$ & ND & ND & ND & ND \\
\hline $\begin{array}{l}\text { Gibberellic acid }(10 \mu \mathrm{M})+ \\
\text { Triadimefon }(1 \mu \mathrm{M})\end{array}$ & $\begin{array}{c}26.6 \pm 7.0^{\mathrm{b}, \mathrm{d}} \\
(93.3)\end{array}$ & $10.6 \pm 2.7^{d}$ & ND & ND & ND & ND \\
\hline
\end{tabular}

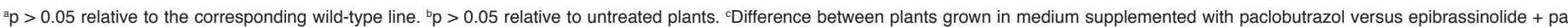

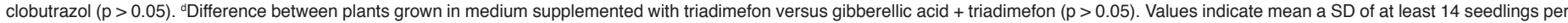
line. The Student $t$-test was used to generate $p$ values. The percentage of non-ectopic stomata is indicated in parentheses. ND, not determined. 
TABLE 2

\section{NUMBER OF STOMATA IN THE HYPOCOTYLS OF WILD-TYPE AND MUTANT SEEDLINGS GROWN WITH OR WITHOUT CHEMICAL TREATMENTS}

\begin{tabular}{|c|c|c|c|c|c|}
\hline Number of stomata per hypocotyl & Ler & Ws-2 & gl2-1 (in Ler) & $c p c$ (in Ws-2) & try cpc (in Ler) \\
\hline Without chemical treatment & $19.0 \pm 5.1(96.7)$ & $30.0 \pm 5.4(93.3)$ & $32.0 \pm 8.4^{\mathrm{a}}(73.3)$ & $14.0 \pm 2.3^{\mathrm{a}}(93.3)$ & $1.0 \pm 2.8^{\mathrm{a}}(90.0)$ \\
\hline Gibberellic acid $(10 \mu \mathrm{M})$ & $34.0 \pm 7.3^{\mathrm{b}}(93.3)$ & $40.0 \pm 9.0^{\mathrm{b}}(100)$ & $47.0 \pm 10.0^{\mathrm{ab}}(70.0)$ & $25.0 \pm 9.0^{\mathrm{ab}}(90.0)$ & $2.0 \pm 4.1^{\mathrm{a}}(89.5)$ \\
\hline Paclobutrazol $(0.5 \mu \mathrm{M})$ & $13.0 \pm 5.5^{\mathrm{b}}(100)$ & $23.0 \pm 6.2^{b}(100)$ & $23.0 \pm 6.7^{\mathrm{ab}}(76.7)$ & $14.0 \pm 4.0^{\mathrm{a}}(90.0)$ & $2.0 \pm 4.3^{\mathrm{a}}(90.0)$ \\
\hline
\end{tabular}

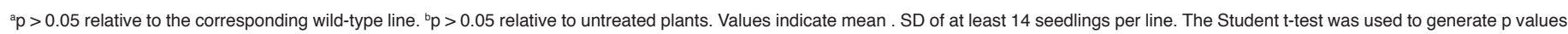
The percentage of non-ectopic stomata is indicated in parentheses.

files overlying two cortical cell files (Table 1), which could favor gas exchange between the atmosphere and the internal tissues.

\section{Gibberellins do not reverse the lack of stomata in the tmm-1 hypocotyl}

The tmm-1 hypocotyl develops meristemoids that are unable to develop into stomata (Bhave et al., 2009). To determine whether gibberellins reverse this $\mathrm{tmm}$-1-dependent defect, we grew $\mathrm{tmm}$-1 seedlings on medium supplemented with gibberellic acid. Treatment with $10 \mu \mathrm{M}$ gibberellic acid increased stomatal production in wild-type plants but failed to induce stomatal formation in tmm-1 (Fig. $1 \mathrm{~A}$ ). The length of the hypocotyl of both wild-type plants and tmm-1 mutant increased significantly in response to gibberellic acid (Fig. $1 \mathrm{~B}$ ). These results support the notion that gibberellins promote stomatal pathway initiation, whereas $T M M$ is required for meristemoid progression.

\section{Gibberellins control GL2 and CPC expression}

To determine the effects of gibberellins on the expression of genes in the MYBs-TTG-bHLHs-GL2network, we investigated the expression of $G L 2$, a negative regulator of stomatal development (Berger et al., 1998; Hung et al., 1998), and CPC, a promoter of this process (Serna, 2008). In wild-type plants, the GL2promoter is preferentially induced in the upper portion of non-stomata-forming cell files (Hung et al., 1998). When plants were grown in the presence of $10 \mu \mathrm{M}$ gibberellic acid, the pattern of GFP expression, driven by the GL2 promoter, was indistinguishable from that of untreated plants: GFP activity detected in non-stomata-forming cell files but not in stomata-forming cells files (Fig. $2 \mathrm{~A}$ and $\mathrm{B}$ ). However, plants treated with $0.5 \mu \mathrm{M}$ paclobutrazol exhibited GL2:GFP expression also in some cells of stomata-forming cell files (Fig. 2C). This result indicates that gibberellins repress GL2 promoter activity in stomata-forming cell files.

The $C P C$ promoter is also preferentially induced in the upper portion of non-stomata-forming cell files (Kirik et al., 2004; Serna, 2008). When plants were grown in medium supplemented with $10 \mu \mathrm{M}$ gibberellic acid, the pattern of CPC:GFP expression was identical to that of untreated plants (Fig. $2 \mathrm{D}$ and E). However, CPC:GFP expression extended to all files in plants treated with $0.5 \mu \mathrm{M}$ paclobutrazol (Fig. $2 \mathrm{~F}$ ). These data indicate that gibberellins repress $C P C$ promoter activity in stomata-forming cell files.

\section{Gibberellins do not reverse the low number of stomata in the try cpc hypocotyl}

Treatment with $10 \mu \mathrm{M}$ gibberellic acid increased the number of stomata in the hypocotyl of both Ler and Ws-2 ecotypes (Table
2). In addition, the reduction of gibberellin biosynthesis with 0.5 $\mu \mathrm{M}$ paclobutrazol reduced stomatal formation in these ecotypes (Table 2). Under all growth media, stomata of both Ler and Ws-2 ecotypes were mainly placed in epidermal cell files that overly two cortical cell files (Table 2). The gl2 mutant (gl2-1) develops an increased number of stomata compared to wild-type seedlings,

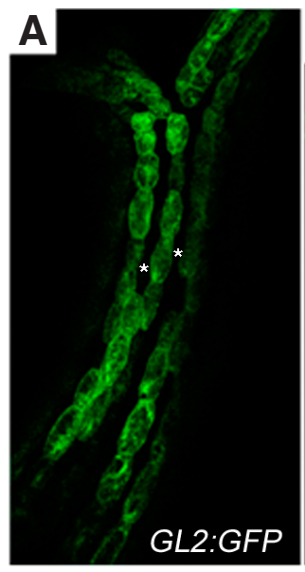

Control

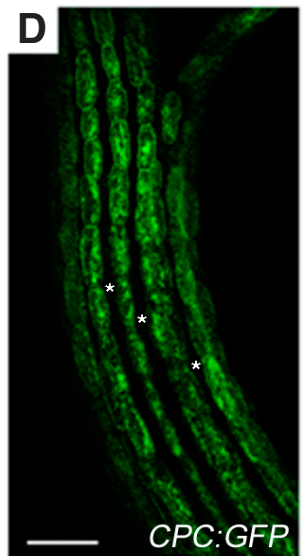

Control

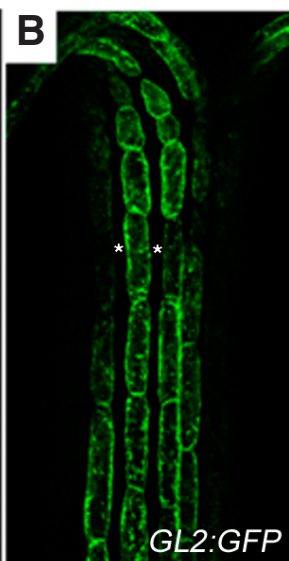

$10 \mu \mathrm{M}$ gibberellic acid

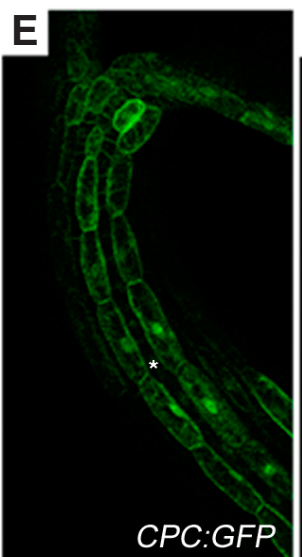

$10 \mu \mathrm{M}$

gibberellic acid

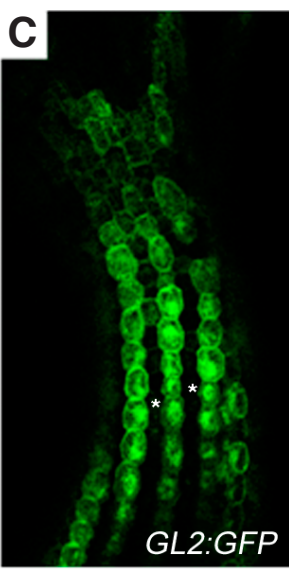

$0.5 \mu \mathrm{M}$ paclobutrazol

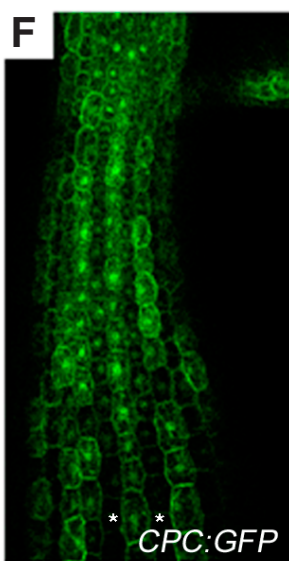

$0.5 \mu \mathrm{M}$

paclobutrazol
Fig. 2. Effect of gibberellic acid on both (A-C) GL2:GFP and (D-F) CPC:GFP expression. Asterisks indicate stomatal-forming cell files. Scale bars, $50 \mu \mathrm{m}$; all images were photographed at the same magnification. GFP was excited with an argon laser at $488 \mathrm{~nm}$. GFP emission was detected by setting the spectral detector between 500 and $525 \mathrm{~nm}$. 
with many of the stomata located in files placed outside of a single cortical cell file (Berger et al., 1998; Table 2). This mutant exhibited increased stomatal production when $10 \mu \mathrm{M}$ gibberellic acid was added to the growth medium but reduced stomatal production on growth medium supplemented with $0.5 \mu \mathrm{M}$ paclobutrazol (Table 2). On all growth media, stomatal production was higher in the gl2-1 mutant than in wild-type seedlings, with many of its stomata found in ectopic positions (Table 2).

The $c p c$ mutant exhibits a reduced number of stomata compared with wild-type plants (Serna, 2008; Table 2). Treatment with $10 \mu \mathrm{M}$ gibberellic acid caused an increase in the number of stomata in the $c p c$ mutant (Table 2). However, try $c p c$, which develops a very low number of stomata (Serna, 2008; Table 2), was insensitive to gibberellic acid (Table 2). Under all growth conditions, stomata of both $c p c$ and try $c p c$ were mainly located in epidermal cell files that overly two cortical cell files (Table 2). These results suggest that $C P C$ and $T R Y$ redundantly regulate stomatal production downstream of gibberellic acid. Treatment with $0.5 \mu \mathrm{M}$ paclobutrazol did not reduce the low stomatal production in the cpc mutant (Table 2).

\section{Discussion}

Both brassinosteroids and gibberellins control stomatal formation in the embryonic stem (Saibo et al., 2003; Fuentes et al., 2012; Gudesblat et al., 2012), suggesting that their signaling pathways may interact. Crosstalk occurs between these plant regulators through a direct interaction between the brassinosteroids-activated BZR1 and gibberellic acid-inactivated DELLA transcriptional regulators to regulate plant growth (Bai et al., 2012; Gallego-Bartolomé et al., 2012; Li et al., 2012). However, the finding that brassinosteroids regulate stomatal development independent of BZR1 and BRASSINOSTEROID INSENSITIVE1EMS-SUPPRESSOR1 (BES1; Gudesblat et al., 2012) suggests the existence of an alternative and upstream point of interaction between these two signaling pathways. Epibrassinolide partially rescued stomatal formation in the gid1a-2 gid1b-3 gid 1c-1

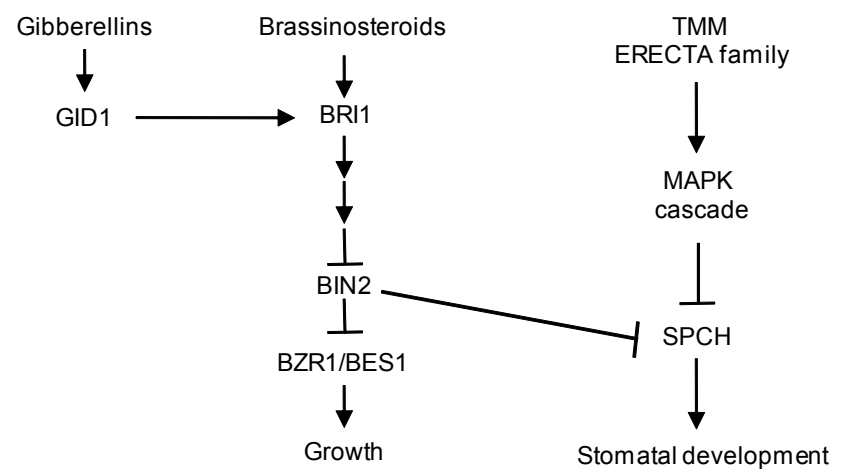

Fig. 3. Model of the genetic and hormonal control of stomatal development in the hypocotyl. The gibberellin signaling pathway interacts, through GID1 or downstream components, with the brassinosteroid signaling pathway directly with (and/or upstream of) BRI1, which negatively regulates BIN2. Low mitogen-activated protein kinase (MAPK) levels in the hypocotyl allow gibberellins promote stomatal development by negatively regulating the BIN2 repression of SPEECHLESS (SPCH). Arrows indicate positive regulation; blunted lines indicate negative action. triple mutant, suggesting that gibberellins function upstream of brassinosteroids (Fig. 3). The absence of a significant effect of gibberellins on the bri1-1 mutant strongly supports this suggestion, and suggests that gibberellin signaling pathway interacts with the brassinosteroid signaling pathway upstream of, and/or directly with, BRI1. Consistent with this interpretation, epibrassinolide- and paclobutrazol-treated plants developed more stomata than paclobutrazol-treated plants. Strikingly, treatment with gibberellic acid and triadimefon rescued the stomatal production of triadimefon-treated plants. One possible explanation for this finding is that, as suggested by Asami and co-workers (2003), triadimefon may affect both brassinosteroid and gibberellin biosynthesis. Low mitogen-activated protein kinase levels could allow brassinosteroids, through their regulation by gibberellins, promote stomatal development by inhibiting the GLYCOGEN SYNTHASE KINASE-like BRASSINOSTEROID INSENSITIVE2(BIN2) repression of SPEECHLESS (Serna, 2013; Fig. 3).

A number of findings have also increased our understanding of the potential interactions between gibberellins and the MYBsbHLHs-TTG-GL2 network. Although the $c p c$ mutant increased stomatal production in response to gibberellic acid treatment, the try $c p c$ mutant showed absolute insensitivity to this phytohormone. It is therefore likely that gibberellic acid promotes stomatal development upstream of $C P C$ and $T R Y$ and that $c p c$ responds to this hormone because of genetic redundancy. The response of the gl2-1 mutant to changes in both gibberellin and brassinosteroid levels is striking. One possible explanation is that unidentified genes might perform the functions of GL2 in the gl2-1 mutant background. In agreement with this suggestion, paclobutrazol treatment promoted GL2 expression also in some cells of stomatal-forming cell files. In these cells, the absence (or low levels) of gibberellins may block stomatal development. Unexpectedly, paclobutrazol treatment promoted CPC promoter induction also in cells of stomatal-forming cell files. This finding suggests that CPC controls unidentified processes in these cells, and that $C P C$ expression does not necessarily trigger stomatal formation. Post-transcriptional modification of CPC in non-stomatalforming cell files may be required to induce stomatal development. Gibberellins then most probably function upstream of the TTG/ $b H L H s / M Y B s / G L 2$ network to regulate GL2 and CPC expression. Brassinosteroids also act upstream of $C P C$ and $G L 2$ (Fuentes et al., 2012), but their effects are not identical to those mediated by gibberellins. This indicates that gibberellins do not regulate the expression of these genes through brassinosteroid signaling.

TMM regulates stomatal development, with $\mathrm{tmm}$ - 1 developing arrested meristemoids and lacking stomata (Bhave et al., 2009). Gibberellins, like brassinosteroids (Fuentes et al., 2012; Gudesblat et al., 2012), cannot induce stomatal formation in tmm-1. These two phytohormones control the initiation of stomatal development, and $T M M$ functions in later stages, inducing stomatal formation from meristemoids. In agreement with this interpretation, gid1a-2 gid1b-3 gid1c-, as well as paclobutrazol- and triadimefon-treated wild-type plants, do not have arrested meristemoids. The number of meristemoids in tmm-1 is smaller than the number of stomata in wild-type plants (Fuentes et al., 2012), suggesting that TMM also promotes entrance into the stomatal pathway. TMM may reduce mitogen-activated protein kinase activity in the embryonic stem, which would prevent the regulation of SPEECHLESS by BIN2 to promote stomatal development (Serna, 2013). 


\section{Materials and Methods}

\section{Plant materials and growth conditions}

Mutant plants used in this work include bri1-1 (N3723), gid1a-2 gid1b-3 gid1c-1 (N16297), tmm-1 (N6140), gl2-1 (N65), cpc, and try cpc. Transgenic plants carrying either the GL2:GFP (Lin and Schiefelbein, 2001; Fuentes et al., 2012) or CPC:GFP (Fuentes et al., 2012) construct were also used. The wild-type strains included Wassilewskija (Ws-2), Columbia (Col-0), and Landsberg erecta (Ler).

Vernalized seeds were sterilized using $5 \%$ sodium hypochlorite and sown on plates containing $1 \%$ agar, $1 \%$ sucrose, and Murashige and Skoog salts. Some media were supplemented with epibrassinolide, triadimefon, gibberellic acid, and/or paclobutrazol. Seedlings were grown for 2 weeks on horizontally oriented dishes in the light ( 16 hour light/8 hour dark cycle) at $22{ }^{\circ} \mathrm{C}$.

Sterile seeds from gid1a-2 gid1b-3 gid1c-1 were sown on plates containing Murashige and Skoog salts medium. The seed coats of non-germinating gid1a-2 gid1b-3 gid1c-1 seeds were manually removed. Dissected embryos were plated on Murashige and Skoog medium containing 1\% sucrose with (or without) epibrassinolide.

\section{Characterization of epidermal features}

Two-week-old seedlings were examined and digitized under Nomarski optics to determine the total number of stomata per hypocotyl. Stomata placed in epidermal files that contacted a single cortical cell file were defined as ectopics, and those in files making contact with two cortical cell files were defined as non-ectopics (Berger et al., 1998; Hung et al., 1998). To determine the percentage of ectopic (or non-ectopic) stomata, two randomly selected stomata per hypocotyl (at least 14 seedlings) were examined by focusing alternatively on the epidermal and cortical focal planes.

The ratio of the number of stomata in a given file divided by the total number of stomata and other epidermal cells in that same file (stomatal index) was also determined. Two cell files per plant, and at least 14 plants, were analyzed. All samples were examined by light microscopy with a Leica DC 300F camera attached to a Leica DMIRB inverted microscope. Images were acquired with the Leica Application Suite and processed with Adobe Photoshop.

\section{GFP imaging}

Three-day-old seedlings were used to visualize GFP fluorescence. GFP was excited at $488 \mathrm{~nm}$ using an argon laser, and fluorescence was monitored with an emission window setting of 500-525 nm. GFP fluorescence acquisition was performed using the $40 x / 1.15$ Oil CS 0.17/E,0.27 ACS APO objective of a DMIRB inverted Leica TCS SP-II confocal microscope. Images, recorded with a picture size of $1024 \times 1024$ pixels, were arranged and labeled using Adobe Photoshop.

\section{Author Contributions}

L.S. conceived and supervised this study. D.G. and S.F. performed all experiments and related analyses.

\section{Acknowledgments}

We thank L. Dolan and J. Schiefelbein for kindly providing us with the CPC:GFP and GL2:GFP plants and M. Hülskamp for the try and try cpc mutants. This work was supported by a grant from the Communities Council of Castilla-La Mancha (PEll11-0141-1629).

\section{References}

ASAMI, T., MIZUTANI, M.M., SHIMADA, Y., GODA, H., KITAHATA, N., SEKIMATA, K., HAN, S.Y., FUJIOKA, S., TAKATSUTO, S., SAKATA, K., etal., (2003). Triadimefon, a fungicidal triazole-type P450 inhibitor, induces brassinosteroid deficiency-like phenotypes in plants and binds to DWF4 protein in the brassinosteroid biosynthesis pathway. Biochem J 369: 71-76.

BAI, M.-Y., SHANG, J.-X., OH, E., FAN, M., BAI, Y., ZENTELLA, R., SUN, T.-P. and WANG, Z.-Y. (2012). Brassinosteroid, gibberellin and phytochrome impinge on a common transcription module in Arabidopsis. Nat Cell Biol 14: 810-817.

BERGER, F., LINSTEAD, P., DOLAN, L. and HASELOFF, J. (1998). Stomata patterning on the hypocotyl of Arabidopsis Thaliana is controlled by genes involved in the control of root epidermis patterning. Dev Biol 194: 226-234.

BHAVE, N.S., VELEY, K.M., NADEAU, J.A., LUCAS, J.R., BHAVE, S.L. and SACK FD. (2009). TOO MANY MOUTHS promotes cell fate progression in stomatal development of Arabidopsis stems. Planta 229: 357-367.

DI CRISTINA, M.D., SESSA, G., DOLAN, L., LINSTEAD, P., BAIMA, S., RUBERTI, I. and MORELLI, G. (1996). The Arabidopsis Athb-10 (GLABRA2) is an HD-Zip protein required for regulation of root hair development. Plant J 10: 393-402.

FUENTES, S., CAÑAMERO, R.C. and SERNA, L. (2012). Relationship between brassinosteroids and genes controlling stomatal production in the Arabidopsis hypocotyl. Int J Dev Biol 56: 675-680.

GALLEGO-BARTOLOMÉ, J., MINGUET, E.G., GRAU-ENGUIX, F., ABBAS, M., LOCASCIO, A., THOMAS, S.G., ALABADÍ, D. and BLÁZQUEZ, M.A. (2012). Molecular mechanism for the interaction between gibberellin and brassinosteroid signaling pathways in Arabidopsis. Proc Natl Acad Sci USA 109: 13446-13451.

GEISLER, M., YANG, M. and SACK, F.D. (1998). Divergent regulation of stomatal initiation and patterning in organ and suborgan regions of the Arabidopsis mutants too many mouths and four lips. Planta 205: 522-530.

GUDESBLAT, G.E., SCHNEIDER-PIZON, J., BETTI, C., MAYERHOFER, J., VANHOUTTE, I., VAN DONGEN, W., BOEREN, S., ZHIPONOVA, M., DE VRIES, S., JONAK C. et al., (2012). SPEECHLESS integrates brassinosteroid and stomata signalling pathways. Nat Cell Biol 14: 548-554.

HUNG, C.-Y., LIN, Y., ZHANG, M., POLLOCK, S., MARKS, M.D. and SCHIEFELBEIN, J. (1998). A common position-dependent mechanism controls cell-type patterning and GLABRA2 regulation in the root and hypocotyl epidermis of Arabidopsis. Plant Physiol 117: 73-84.

KIRIK, V., SIMON, M., HUELSKAMP, M. and SCHIEFELBEIN, J. (2004). The ENHANCER OF TRY AND CPC1 gene acts redundantly with TRIPTYCHON and CAPRICE in trichome and root hair cell patterning in Arabidopsis. Dev Biol 268: 506-513.

LARKIN, J.C., BROWN, M.L. and SCHIEFELBEIN, J. (2003). How cells know what they want to be when they grow up? Lessons from epidermal patterning in Arabidopsis. Annu Rev Plant Biol 54: 403-430.

LI, Q.F., WANG, C., JIANG, L., LI, S., SUN, S.S. and HE, J.X. (2012). An interaction between BZR1 and DELLAs mediates direct signaling crosstalk between brassinosteroids and gibberellins in Arabidopsis. Science Signaling 5, ra72 doi: 10.1126/scisignal.2002908.

LIN, Y. and SCHIEFELBEIN, J. (2001). Embryonic control of epidermal cell patterning in the root and hypocotyl of Arabidopsis. Development 128: 3697-705.

NADEAU, J.A. and SACK, F.D. (2002). Control of stomatal distribution on the Arabidopsis leaf surface. Science 296: 1697-1700.

NASEEM, M., KALTDORF, M. and DANDEKAR, T. (2015). The nexus between growth and defence signalling: auxin and cytokinin modulate plant immune response pathways. J Exp Bot 66: 4885-4896.

RADEMACHER W. (2000). Growth retardants: effects on gibberellin biosynthesis and other metabolic pathways. Annu Rev Plant Physiol Plant Mol Biol 51: 501-531.

RERIE, W.G., FELDMANN, K.A. and MARKS, M.D. (1994). The GLABRA2 gene encodes a homeodomain protein required for normal trichome development in Arabidopsis. Genes Dev 8: 1388-1399.

SAIBO, N.J., VRIEZEN, W.H., BEEMSTER, G.T. and VAN DER STRAETEN, D. (2003). Growth and stomata development of Arabidopsis hypocotyls are controlled by gibberellins and modulated by ethylene and auxins. Plant J 33: 989-1000.

SCHIEFELBEIN, J. (2003). Cell-fate specification in the epidermis: a common patterning mechanism in the root and shoot. Curr Opin Plant Biol 6: 74-78.

SERNA, L. (2004 a). Epidermal cell patterning and differentiation throughout the apical-basal axis of the seedling. J Exp Bot 56: 1983-1989.

SERNA, L. (2004 b). A network of interacting factors triggering different cell fates. Plant Cell 16: 2258-2263.

SERNA, L. (2008). CAPRICE positively regulates stomatal formation in the Arabidopsis hypocotyl. Plant Signal Behav 3: 1-6.

SERNA, L. (2013). What causes opposing actions of brassinosteroids on stomatal development? Plant Physiol 162: 3-8.

VERT, G., WALCHER, C.L., CHORY, J. and NEMHAUSER, J.L. (2008). Integration of auxin and brassinosteroid pathways by Auxin Response Factor 2. Proc Nat Acad Sci USA 105: 9829-9834. 


\section{Further Related Reading, published previously in the Int. J. Dev. Biol.}

Gene targeting in plants: 25 years later

Holger Puchta and Friedrich Fauser

Int. J. Dev. Biol. (2013) 57: 629-637

https://doi.org/10.1387/ijdb.130194hp

The use of fluorescence-activated cell sorting in studying plant development and environmental responses

Anthony D. Carter, Roxanna Bonyadi and Miriam L. Gifford

Int. J. Dev. Biol. (2013) 57: 545-552

https://doi.org/10.1387/ijdb.130195mg

Relationship between brassinosteroids and genes controlling stomatal production in the Arabidopsis hypocotyl Sonia Fuentes, Roberto C. Cañamero and Laura Serna

Int. J. Dev. Biol. (2012) 56: 675-680

https://doi.org/10.1387/ijdb.120029ls

Reproductive Meristem22 is a unique marker for the early stages of stamen development Elisson Romanel, Pradeep Das, Richard M. Amasino, Jan Traas, Elliot Meyerowitz and Marcio Alves-Ferreira

Int. J. Dev. Biol. (2011) 55: 657-664

https://doi.org/10.1387/ijdb.113340er

Multi-probe in situ hybridization to whole mount Arabidopsis seedlings

Leonardo Bruno, Antonella Muto, Natasha D. Spadafora, Domenico laria, Adriana Chiappetta, Mieke Van Lijsebettens and Maria B. Bitonti

Int. J. Dev. Biol. (2011) 55: 197-203

https://doi.org/10.1387/ijdb.103132lb

Stomatal development in Arabidopsis and grasses: differences and commonalities Laura Serna

Int. J. Dev. Biol. (2011) 55: 5-10

https://doi.org/10.1387/ijdb.103094ls
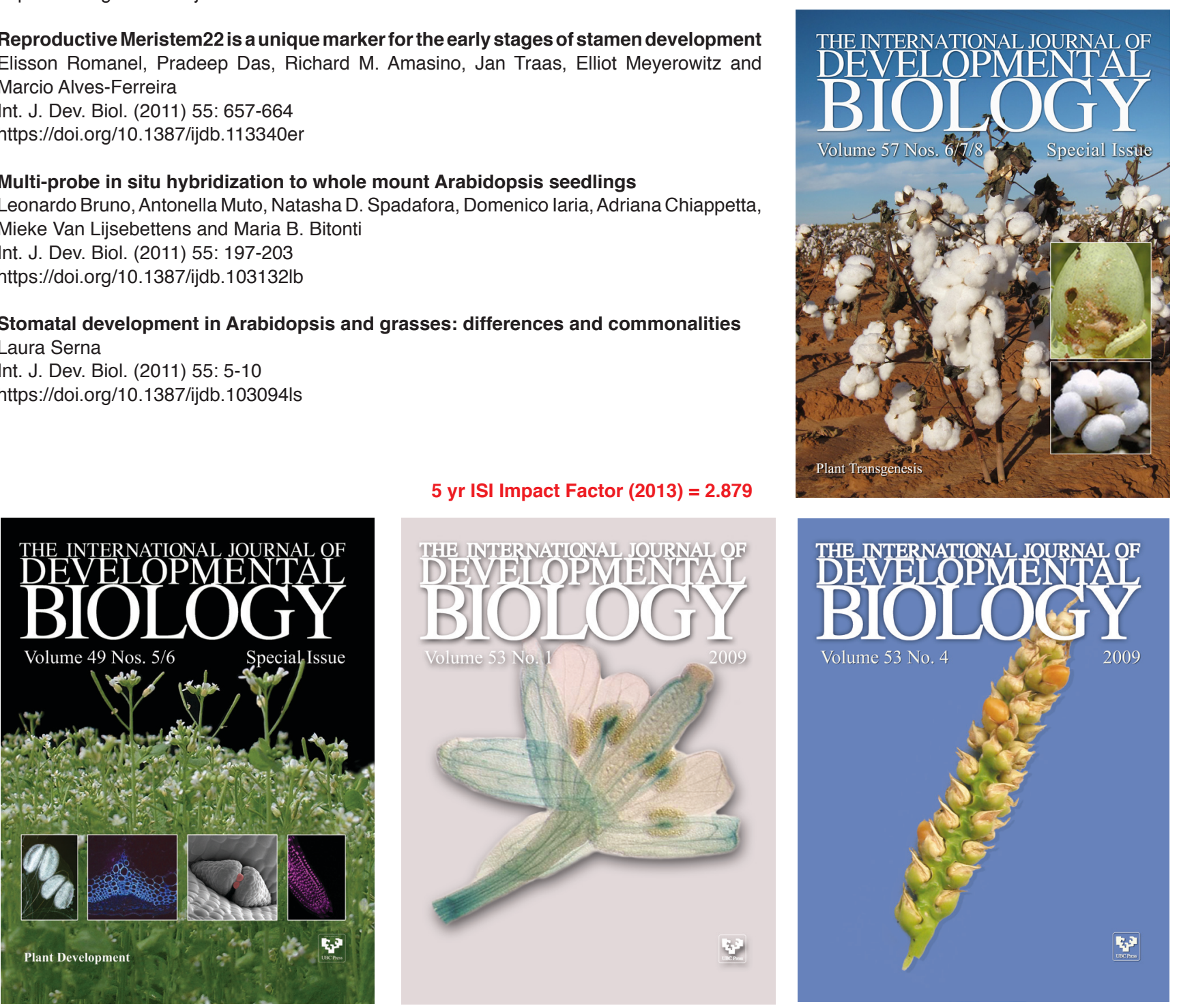